\title{
Combined and interaction effect of chlamydia pneumoniae infection and smoking on lung cancer: a case-control study in Southeast China
}

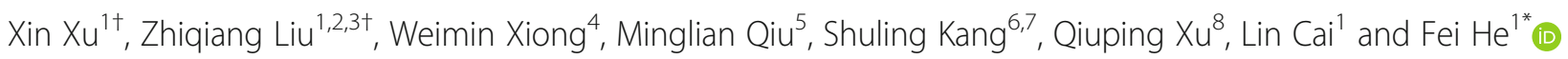

\begin{abstract}
Background: This case-control study investigated the role of Chlamydia pneumoniae (Cpn) infection in the pathogenesis of lung cancer and the combined and interaction effect of Cpn infection, smoking, and various environmental factors.
\end{abstract}

Methods: The study comprised 449 lung cancer patients and 512 age- and sex-matched healthy controls. All participants provided a $5 \mathrm{ml}$ fasting peripheral venous blood sample for testing Cpn-specific IgG and IgA by using micro-immunofluorescence. Besides analyzing the associations between Cpn and lung cancer, combined effect analysis, logistic regression, and the Excel table made by Andersson were used to analyze the combined and interaction effects of Cpn and environmental factors on lung cancer.

Results: Compared to those with no evidence of serum Cpn IgA or Cpn IgG, those with both Cpn IgG+ and IgA+ had 2.00 times the risk (95\% Cl: 1.34-3.00) of developing lung cancer. Cpn IgG+ or IgA+ was associated with a significantly increased risk of lung cancer among smokers; the adjusted odds ratio (OR) was 1.79 (95\% Cl: 1.10-2.91) and 2.27 (95\% Cl: 1.38-3.72), respectively. Those exposed to passive smoking with Cpn IgG+ or IgA+ also showed an increased risk of lung cancer; the adjusted OR was 1.82 (95\% Cl: 1.20-2.77) or 1.87 (95\% Cl: 1.22-2.87), respectively. Similar results were also observed among alcohol drinkers. Multiplicative and additive interactions were not observed between Cpn infection and environmental factors. The combined effects of Cpn lgG+ or lgA+ with smoking, passive smoking, and family history of cancer on lung cancer were determined.

Conclusion: Cpn infection is potentially associated with primary lung cancer in the Chinese Han population and has combined effects with smoking, passive smoking, and family history of cancer.

Keywords: Chlamydia pneumoniae infection, Case-control study, Environmental factors, Lung cancer

\footnotetext{
* Correspondence: ifeihe@163.com

${ }^{+}$Xin Xu and Zhiqiang Liu contributed equally to this work.

'Department of Epidemiology and Health Statistics, School of Public Health, Fujian Medical University, Fuzhou 350108, China

Full list of author information is available at the end of the article
}

C C The Author(s). 2020 Open Access This article is licensed under a Creative Commons Attribution 4.0 International License, which permits use, sharing, adaptation, distribution and reproduction in any medium or format, as long as you give appropriate credit to the original author(s) and the source, provide a link to the Creative Commons licence, and indicate if changes were made. The images or other third party material in this article are included in the article's Creative Commons licence, unless indicated otherwise in a credit line to the material. If material is not included in the article's Creative Commons licence and your intended use is not permitted by statutory regulation or exceeds the permitted use, you will need to obtain permission directly from the copyright holder. To view a copy of this licence, visit http://creativecommons.org/licenses/by/4.0/ The Creative Commons Public Domain Dedication waiver (http://creativecommons.org/publicdomain/zero/1.0/) applies to the data made available in this article, unless otherwise stated in a credit line to the data. 


\section{Background}

Lung cancer is the most commonly diagnosed cancer (11.6\% of all cases) and the leading cause of cancer death (18.4\% of all cancer deaths) worldwide, with greater than $80 \%$ of lung cancers in western populations attributed to smoking [1]. Recently, studies on other causes of lung cancer, such as infections and respiratory diseases, have been increasing in number [2].

Infection is the third leading cause of cancer worldwide [3]. Chronic inflammation resulting from various persistent infections is known to place a person at risk for malignancy. The etiologic role of chronic lung inflammation in lung cancer development has been established [4, 5]. Moreover, chronic lung infections can increase lung cancer risk independently and in conjunction with tobacco smoke exposure [4]. Chlamydia species, including Chlamydia pneumoniae (Cpn), Chlamydia trachomatis (Ctr), and Chlamydia psittaci (Cps), can also cause persistent infections and chronic inflammation, which may play an essential role in lung cancer pathogenesis. Cpn can cause pneumonia and other respiratory infections, and repeated or prolonged exposure to Chlamydia antigens may cause chronic obstructive pulmonary disease, asthma, and lung cancer. Several studies have examined the association between Cpn infection and lung cancer [6-16] but failed to identify the combined and interaction effect of Cpn infection with environmental factors, which is of great value.

This study aimed to evaluate the role of Cpn infection in the pathogenesis of lung cancer and to investigate the combined and interaction effect of Cpn infection and environmental factors on lung cancer.

\section{Methods}

\section{Cases and controls}

Lung cancer cases were identified from the Department of Thoracic Surgery and Respiratory Medicine of The First Affiliated Hospital of Fujian Medical University, Fujian Medical University Union Hospital, and Fuzhou General Hospital of Nanjing Military Command between December 2006 and December 2016. Inclusion criteria: (1) newly diagnosed primary lung cancer by fiberoptic bronchoscopy or histopathologic evaluation, and (2) lived in the Fujian province of China for more than 10 years. Exclusion criteria: (1) pathologic diagnosis of lung inflammation, benign lesion, or secondary lung cancer, and (2) could not answer the study questions.

Controls were frequency matched based on the age and sex of cases. During the same study period, healthy community dwellers were selected for the control group. Inclusion criteria: (1) lived in Fujian province for more than 10 years, (2) no history of tumor, and (3) no family member participated as a case of this study. In total, 449 lung cancer cases and 512 healthy controls were included in this study. The participation rate was $97 \%$ for patients and $90 \%$ for control subjects. The Institutional Review Board of Fujian Medical University (Fuzhou, China) approved this study, and all participants signed informed consent forms.

\section{Survey content and variables}

This is an ongoing case-control study and the detail of the questionnaire had been published previously [17]. All epidemiological data were obtained through face-toface interviews using a standardized questionnaire, which collected information on baseline demographic characteristics, body mass index (BMI), smoking, passive smoking, alcohol consumption, tea drinking, history of lung diseases, family history of cancer, occupational physical activity, physical exercise, cooking oil fume exposure, and pollution near the residence.

Smoking was defined as having smoked more than 100 cigarettes in their lifetime. Passive smoking was defined as non-smokers who were exposed to inhaled cigarette smoke or exhaled smoke more than once per day for more than $15 \mathrm{~min}$ per day. Alcohol consumption was defined as drinking at least one alcoholic beverage per week for more than 6 months, regardless of alcoholic drink type. Drinking tea was defined as consuming at least one cup per week for more than 6 months. A family history of cancer was defined as the occurrence of a malignant tumor in first-degree or second-degree relatives. Occupational physical activity was rated as low, moderate, or high intensity, following the Reference Standard of Labor Intensity recommended by the Chinese Nutrition Society in 2000 [18]. Participants were asked about fumes in their kitchens during cooking for evaluating cooking oil fume exposure.

Before the survey, we trained investigators strictly. Furthermore, the investigators combined their professional knowledge to make a more objective evaluation of the quality of the questionnaire based on the respondents' answers, methods, and attitudes. After the survey, $10 \%$ of the questionnaire was randomly rechecked to verify the authenticity of the survey data.

\section{Experimental methods}

All cases and controls provided a $5 \mathrm{ml}$ fasting peripheral venous blood sample, using non-anticoagulation vacuum blood collection tubes. Samples were immediately processed by centrifugation at $2000 \mathrm{rpm}$ for $10 \mathrm{~min}$, followed by serum separation and storage at $-80^{\circ} \mathrm{C}$.

Cpn-specific IgG and IgA were tested using a microimmunofluorescence (MIF) kit (Chlamydia IgG SeroFIA kit and Chlamydia IgA SeroFIA kit, DADE Behring, Savyon Diagnostics, Israel). Positive chlamydia controls produced a moderate apple-green fluorescent color, whereas negative controls did not fluoresce. A positive result for the presence of chlamydia showed a moderately dispersed apple-green 
fluorescent color; strongly positive results had an intensely glaring apple-green fluorescent color. No fluorescence of any color or a dark background indicated no chlamydial morphology. Although serum Chlamydia IgG and IgA antibody detection are the accepted diagnostic tests for Cpn, MIF test results are subjectively read with the naked eye. To minimize bias, two individuals conducted the experiment: one skilled technician conducted the preliminary experiment, and the second person conducted a blind interpretation of the results. For quality control, $10 \%$ of samples were randomly selected for retesting (Fig. 1).

\section{Statistical analysis}

The Chi-square test was used to compare general characteristics for cases and controls. Stratified analysis and unconditional logistic regression were performed to calculate odds ratios (ORs) and 95\% confidence intervals (CIs) for chlamydia infection and lung cancer risk. The combined effects and multiplication interaction were analyzed by crossover analysis and logistic regression. The method developed by Andersson [19] was used to evaluate the additive interaction, including the relative excess risk of interaction (RERI), attributed proportion of interaction (API), the synergy index (S), and their 95\% CIs. If there is no additive interaction, the $95 \%$ CIs of the RERI and API each contain 0, and the 95\% CI of S contains 1 . The SPSS 24.0 software package (IBM Corporation, Armonk, New York, USA) was used. All $P$ values were based on a two-sided test with an $\alpha$ of 0.05 .

\section{Results}

\section{Participant characteristics}

A total of 961 patients were enrolled in this study, including 449 cases and 512 controls. There were no baseline differences between groups concerning sex, age, ethnicity, marital status, tea-drinking, decoration within 10 years, and ventilation status $(P>0.05)$. However, cases and controls did differ concerning educational level, occupation, BMI, smoking, passive smoking, alcohol consumption, history of lung diseases, history of other diseases, family history of cancer, occupational physical activity, physical exercise, cooking oil fume exposure, and pollution near the residence $(P<0.05)$. Of the 449 cases of lung cancer, there were $277(61.7 \%)$ with lung adenocarcinomas, 96 (21.4\%) with squamous cell carcinoma, 38 (8.5\%) with small cell carcinoma, 7 (1.6\%) with adenosquamous carcinoma, $2(0.4 \%)$ with large cell carcinoma, and 29 (6.4\%) with other types (Table 1).
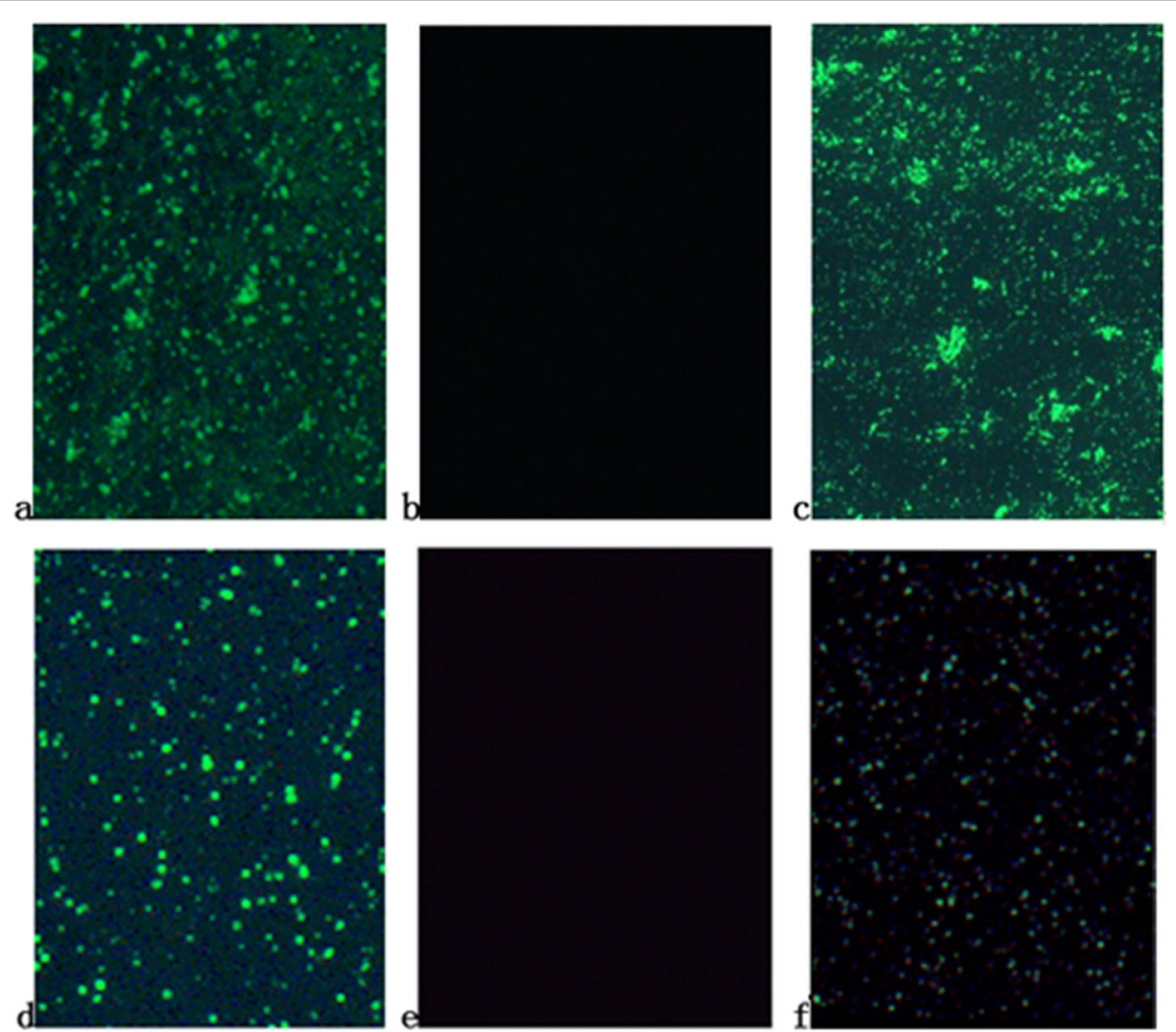

Fig. 1 The detecting results of serum Cpn IgG and IgA by MIF method under the microscope ( $\times 400$ times. a: IgG positive control; b: IgG negative control; c: IgG positive specimens; $\mathbf{d}$ : IgA positive control; e: IgA negative control; f: IgA positive) 
Table 1 Subject characteristics by case and control groups

\begin{tabular}{|c|c|c|c|c|}
\hline Variables & $\begin{array}{l}\text { Cases N (\%) } \\
(N=449)\end{array}$ & $\begin{array}{l}\text { Controls } N(\%) \\
(N=512)\end{array}$ & $x^{2}$ & $P$ \\
\hline Age (years) & & & 0.194 & 0.979 \\
\hline$<45$ & $39(8.7)$ & $43(8.4)$ & & \\
\hline $45 \sim$ & $197(43.9)$ & $229(44.7)$ & & \\
\hline $60 \sim$ & $192(42.7)$ & $214(41.8)$ & & \\
\hline$\geq 75$ & $21(4.7)$ & $26(5.1)$ & & \\
\hline Sex & & & 3.290 & 0.070 \\
\hline Male & $293(65.3)$ & 305 (59.6) & & \\
\hline Female & $156(34.7)$ & $207(40.4)$ & & \\
\hline Ethnicity & & & 0.274 & 0.601 \\
\hline Han & $443(98.7)$ & $507(99.0)$ & & \\
\hline Others & $6(1.3)$ & $5(1.0)$ & & \\
\hline Education & & & 90.131 & $<0.001$ \\
\hline Primary school or less & $231(51.4)$ & $145(28.3)$ & & \\
\hline High school & $174(38.8)$ & 199 (38.9) & & \\
\hline College or higher & $44(9.8)$ & $168(32.8)$ & & \\
\hline Marital status & & & 0.204 & 0.651 \\
\hline Married & $429(95.5)$ & $486(94.9)$ & & \\
\hline Unmarried or others & $20(4.5)$ & $26(5.1)$ & & \\
\hline Occupation & & & 75.731 & $<0.001$ \\
\hline Agriculture, forestry, animal husbandry and fishery personnel & $138(30.7)$ & $80(15.6)$ & & \\
\hline Production transport workers & $109(24.3)$ & $89(17.4)$ & & \\
\hline Enterprises and institutions personnel & $123(27.4)$ & $260(50.8)$ & & \\
\hline Business service personnel & $33(7.4)$ & $58(11.3)$ & & \\
\hline Unemployed or others & $46(10.2)$ & $25(4.9)$ & & \\
\hline $\mathrm{BMI}\left(\mathrm{kg} / \mathrm{m}^{2}\right)$ & & & 11.815 & 0.003 \\
\hline$<18.5$ & $32(7.1)$ & $20(3.9)$ & & \\
\hline $18.5 \sim$ & $278(61.9)$ & $286(55.9)$ & & \\
\hline$\geq 24.0$ & $139(31.0)$ & $206(40.2)$ & & \\
\hline Smoking & & & 68.114 & $<0.001$ \\
\hline No & $188(41.9)$ & $350(68.4)$ & & \\
\hline Yes & $261(58.1)$ & $162(31.6)$ & & \\
\hline Passive smoking & & & 48.699 & $<0.001$ \\
\hline No & $131(29.2)$ & $263(51.4)$ & & \\
\hline Yes & $318(70.8)$ & $249(48.6)$ & & \\
\hline Alcohol consumption & & & 13.787 & $<0.001$ \\
\hline No & $308(68.6)$ & $405(79.1)$ & & \\
\hline Yes & $141(31.4)$ & 107 (20.9) & & \\
\hline Tea drinking & & & 1.255 & 0.263 \\
\hline No & $239(53.2)$ & $254(49.6)$ & & \\
\hline Yes & $210(46.8)$ & $258(50.4)$ & & \\
\hline History of lung diseases & & & 18.235 & $<0.001$ \\
\hline No & $381(84.9)$ & $478(93.4)$ & & \\
\hline Yes & $68(15.1)$ & $34(6.6)$ & & \\
\hline
\end{tabular}


Table 1 Subject characteristics by case and control groups (Continued)

\begin{tabular}{|c|c|c|c|c|}
\hline Variables & $\begin{array}{l}\text { Cases N (\%) } \\
(N=449)\end{array}$ & $\begin{array}{l}\text { Controls N (\%) } \\
(N=512)\end{array}$ & $x^{2}$ & $P$ \\
\hline History of other diseases & & & 5.326 & 0.021 \\
\hline No & $264(58.8)$ & $338(66.0)$ & & \\
\hline Yes & $185(41.2)$ & $174(34.0)$ & & \\
\hline Family history of cancer & & & 5.070 & 0.024 \\
\hline No & $336(74.8)$ & $414(80.9)$ & & \\
\hline Yes & $113(25.2)$ & $98(19.1)$ & & \\
\hline Occupational physical activity & & & 52.066 & $<0.001$ \\
\hline Light & $144(32.1)$ & $278(54.3)$ & & \\
\hline Median & $169(37.6)$ & $150(29.3)$ & & \\
\hline Heavy & $136(30.3)$ & $84(16.4)$ & & \\
\hline Physical exercise & & & 62.254 & $<0.001$ \\
\hline Not often & $316(70.4)$ & $231(45.1)$ & & \\
\hline Usually & $133(29.6)$ & $281(54.9)$ & & \\
\hline Cooking oil fumes & & & 31.925 & $<0.001$ \\
\hline No & $84(18.7)$ & $167(32.6)$ & & \\
\hline Few & $231(51.4)$ & $241(47.1)$ & & \\
\hline Some & $106(23.6)$ & $93(18.2)$ & & \\
\hline Heavy & $28(6.2)$ & $11(2.1)$ & & \\
\hline Decoration within ten years & & & 0.646 & 0.421 \\
\hline No & $278(61.9)$ & $304(59.4)$ & & \\
\hline Yes & $171(38.1)$ & $208(40.6)$ & & \\
\hline Pollution near the residence & & & 27.114 & $<0.001$ \\
\hline No & $368(82.0)$ & $476(93.0)$ & & \\
\hline Yes & $81(18.0)$ & $36(7.0)$ & & \\
\hline Ventilation status & & & 4.272 & 0.118 \\
\hline Bad & $11(2.4)$ & $8(1.6)$ & & \\
\hline General & $48(10.7)$ & $38(7.4)$ & & \\
\hline Well & $390(86.9)$ & $466(91.0)$ & & \\
\hline Pathological types & & & - & - \\
\hline Adenocarcinoma & $277(61.7)$ & - & & \\
\hline Squamous cell carcinoma & $96(21.4)$ & - & & \\
\hline Adenosquamous carcinoma & $7(1.6)$ & - & & \\
\hline Large cell carcinoma & $2(0.4)$ & - & & \\
\hline Small cell carcinoma & $38(8.5)$ & - & & \\
\hline Others & $29(6.4)$ & - & & \\
\hline
\end{tabular}

\section{Chlamydia infection and lung cancer}

The association between Chlamydia infection and lung cancer can be found in Table 2. Patients with serum Cpn IgG showed significantly increased lung cancer risk $(\mathrm{OR}=1.42 ; 95 \% \mathrm{CI}=1.02-1.96)$. Those with serum $\mathrm{Cpn}$ IgA showed significantly increased lung cancer risk $(\mathrm{OR}=1.73 ; 95 \% \mathrm{CI}=1.25-2.38)$. Both $\mathrm{Cpn} \mathrm{IgG}+$ and IgA + were statistically associated with an increased lung cancer risk $(\mathrm{OR}=2.00 ; \quad 95 \% \quad \mathrm{CI}=1.34-3.00)$. No

relationships between other Chlamydia infections (Ctr and Cps) and lung cancer were observed.

Stratified analyses were carried out by age, sex, smoking, passive smoking, drinking, and family history of cancer. Adjustment was made for demographic characteristics and relevant factors. The effect between $\mathrm{Cpn} \operatorname{lgG}+$ and lung cancer was modified by sex $(P=0.049)$. Among men, those with serum Cpn IgG+ were 1.85 times as likely (95\% $\mathrm{CI}=1.21-2.82)$ to develop lung cancer. However, among 
Table 2 The association between Chlamydia infection and lung cancer

\begin{tabular}{|c|c|c|c|c|}
\hline Variables & Cases N (\%) & Controls N (\%) & OR(95\%Cl) & $\mathrm{OR}(95 \% \mathrm{Cl})^{\mathrm{a}}$ \\
\hline \multicolumn{5}{|l|}{ Cpn } \\
\hline \multicolumn{5}{|l|}{ Cpn lgG } \\
\hline$-(<1: 64)$ & $121(26.9)$ & $185(36.1)$ & 1.00 & 1.00 \\
\hline$+(\geq 1: 64)$ & $328(73.1)$ & $327(63.9)$ & $1.53(1.16-2.02)$ & $1.42(1.02-1.96)$ \\
\hline \multicolumn{5}{|l|}{ Cpn IgA } \\
\hline$-(<1: 32)$ & $265(59.0)$ & $376(73.4)$ & 1.00 & 1.00 \\
\hline$+(\geq 1: 32)$ & $184(41.0)$ & $136(26.6)$ & $1.92(1.46-2.52)$ & $1.73(1.25-2.38)$ \\
\hline \multicolumn{5}{|c|}{ Cpn $\lg G$ or $\lg A$} \\
\hline both- & $105(23.4)$ & $161(31.4)$ & 1.00 & 1.00 \\
\hline single+ & $176(39.2)$ & $239(46.7)$ & $1.13(0.83-1.55)$ & $1.07(0.74-1.54)$ \\
\hline both+ & $168(37.4)$ & $112(21.9)$ & $2.30(1.63-3.24)$ & $2.00(1.34-3.00)$ \\
\hline \multicolumn{5}{|l|}{ Ctr } \\
\hline \multicolumn{5}{|l|}{$C \operatorname{tr} \lg G$} \\
\hline$-(<1: 64)$ & $376(83.7)$ & $447(87.3)$ & 1.00 & 1.00 \\
\hline$+(\geq 1: 64)$ & $73(16.3)$ & 65 (12.7) & $1.34(0.93-1.92)$ & $1.04(0.69-1.58)$ \\
\hline \multicolumn{5}{|l|}{$C \operatorname{tr} \lg A$} \\
\hline$-(<1: 32)$ & $443(98.7)$ & $509(99.4)$ & 1.00 & 1.00 \\
\hline$+(\geq 1: 32)$ & $6(1.3)$ & $3(0.6)$ & $2.30(0.57-9.24)$ & $1.32(0.30-5.86)$ \\
\hline \multicolumn{5}{|l|}{ Ctr $\lg G$ or $\lg A$} \\
\hline both- & $373(83.1)$ & $446(87.1)$ & 1.00 & 1.00 \\
\hline single+ & $73(16.3)$ & $64(12.5)$ & $1.36(0.95-1.96)$ & $1.06(0.69-1.61)$ \\
\hline both+ & $3(0.6)$ & $2(0.4)$ & $1.79(0.30-10.79)$ & $1.12(0.17-7.58)$ \\
\hline \multicolumn{5}{|l|}{ Cps } \\
\hline \multicolumn{5}{|l|}{ Cps lgG } \\
\hline$-(<1: 64)$ & $406(90.4)$ & 481 (93.9) & 1.00 & 1.00 \\
\hline$+(\geq 1: 64)$ & $43(9.6)$ & $31(6.1)$ & $1.64(1.02-2.66)$ & $1.28(0.73-2.22)$ \\
\hline \multicolumn{5}{|l|}{ Cps Ig $A$} \\
\hline$-(<1: 32)$ & $444(98.9)$ & 508 (99.2) & 1.00 & 1.00 \\
\hline$+(\geq 1: 32)$ & $5(1.1)$ & $4(0.8)$ & $1.43(0.38-5.36)$ & $1.82(0.41-8.10)$ \\
\hline \multicolumn{5}{|c|}{ Cps lgG or IgA } \\
\hline both- & $404(90.0)$ & $478(93.4)$ & 1.00 & 1.00 \\
\hline single+ & $42(9.4)$ & $33(6.4)$ & $1.51(0.94-2.42)$ & $1.18(0.68-2.05)$ \\
\hline both+ & $3(0.6)$ & $1(0.2)$ & $3.55(0.37-34.26)$ & $4.02(0.36-45.59)$ \\
\hline
\end{tabular}

${ }^{2}$ Adjusted by age, sex, education, occupation, BMI, smoking, passive smoking, alcohol consumption, history of lung diseases, history of other diseases, family history of cancer, occupational physical activity, physical exercise, cooking oil fumes and pollution near the residence

women, the adjusted OR was $0.90(95 \% \mathrm{CI}=0.53-1.53)$. Among men, those with serum Cpn IgA+ were 1.93 times as likely $(95 \% \mathrm{CI}=1.28-2.93)$ to develop lung cancer. Among women, the adjusted OR was $1.54(95 \% \mathrm{CI}=$ $0.91-2.61)$. Those aged 60 years and older with Cpn IgA were 2.42 times more likely to develop lung cancer $(95 \%$ $\mathrm{CI}=1.49-3.92)$. Similarly, among smokers, the risk of developing lung cancer was 1.79 times higher if IgG was positive ( $95 \% \mathrm{CI}=1.10-2.91)$ and 2.27 times higher if IgA was positive ( $95 \% \mathrm{CI}=1.38-3.72$ ). The lung cancer risk of passive smokers was 1.82 times higher if IgG was positive
$(95 \% \mathrm{CI}=1.20-2.77)$ and 1.87 times higher if IgA was positive $(95 \% \mathrm{CI}=1.22-2.87)$. Among alcohol drinkers, those with Cpn IgG+ were 2.45 times as likely to develop lung cancer (95\% CI $=1.27-4.75)$, and those with $\mathrm{Cpn}$ IgA + were 2.68 times as likely to develop lung cancer $(95 \% \mathrm{CI}=1.40-5.13)$ (Fig. 2).

\section{Combined and interaction effects of Cpn IgG or IgA and environmental factors}

After adjustment for possible confounding factors, the results showed that multiplicative and additive interactions 


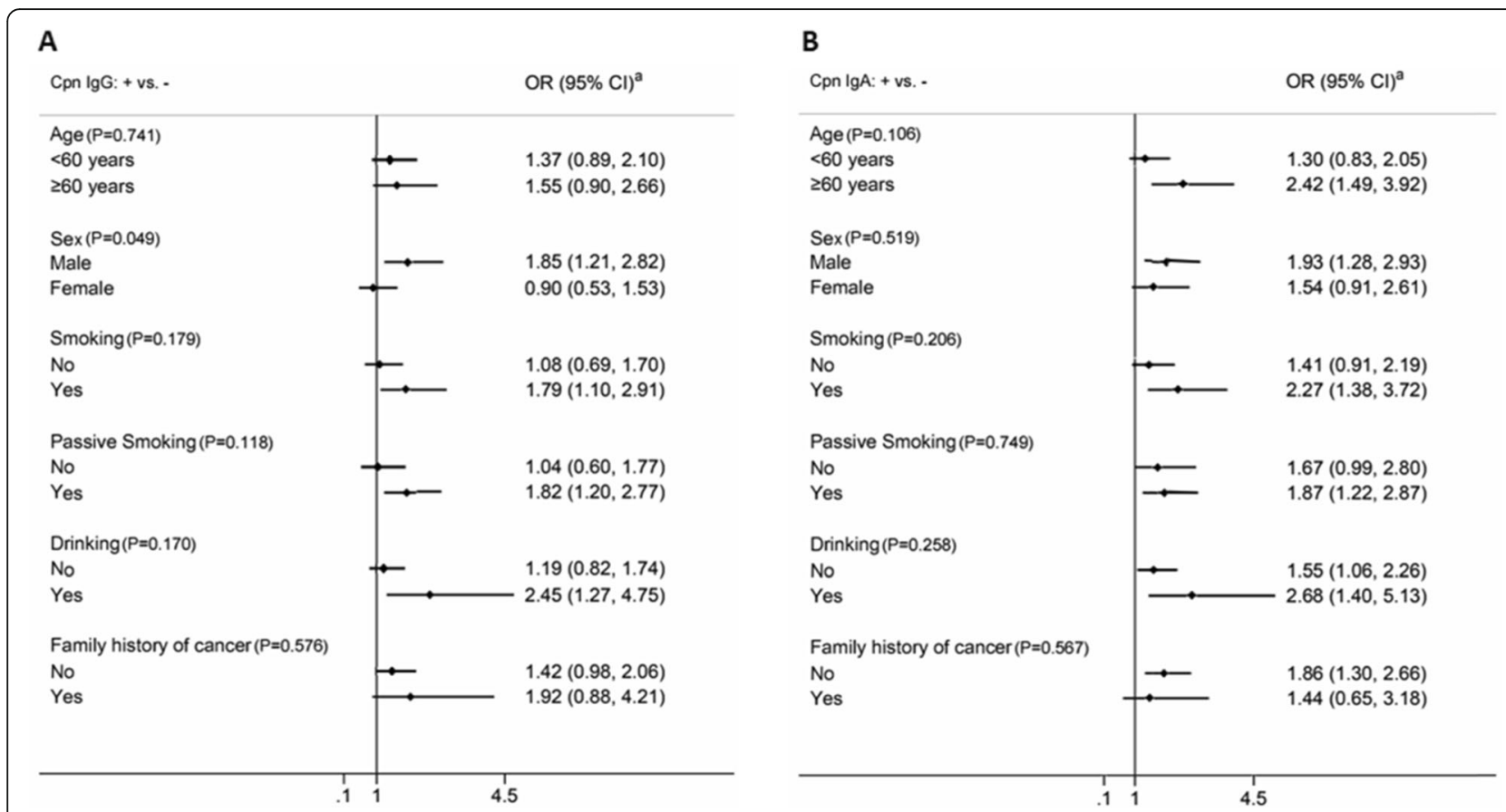

Fig. 2 Stratified analysis of the association between Chlamydia pneumoniae infection and the risk of lung cancer. $\mathbf{a}$ and $\mathbf{b}$ are the results of lgG

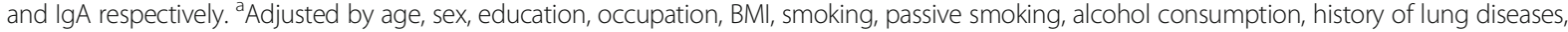
history of other diseases, family history of cancer, occupational physical activity, physical exercise, cooking oil fumes and pollution near the residence

were not observed between Cpn infection and environmental factors. However, the combined effects of Cpn $\operatorname{IgG}+$ or IgA+ and smoking, passive smoking, and family history of cancer on lung cancer were determined (Supplemental Table 1).

\section{Discussion}

The results of this study showed that Cpn infection was associated with the risk of lung cancer. Patients with both serum Cpn IgG+ and IgA+ had 2.00 times the risk of developing lung cancer. The stratified analysis showed that smokers or drinkers with Cpn IgG+ or IgA+ were more likely to develop lung cancer. Additionally, Cpn IgG and IgA each had a combined effect on smoking, passive smoking, and family history of cancer.

Our results were consistent with the results of other studies. Several studies $[6,20,21]$ showed that Cpn infection is associated with a higher risk of lung cancer. Furthermore, other studies [6-8] showed ORs of 1.2 to 2.8 after adjusting for smoking status, indicating that chronic Cpn infection is an independent risk factor for lung cancer. Several case-control studies showed that Cpn infection increased the risk of lung cancer development [10-13, 16] but failed to show a correlation between serum Cpn antibodies and cancer risk [14, 15, 22].

Although it is unclear how Cpn infection would induce or cause lung cancer, the process may involve chronic inflammation. Chronic $\mathrm{Cpn}$ infections may prolong inflammatory mediator stimulation to increase cell necrosis, apoptosis, and mitosis. Thus, the relationship between Cpn infection and lung cancer seems biologically plausible. Furthermore, Cpn proteins have been shown to trigger lung cancer growth potential by altering host cellular replication, transcription, and DNA damage repair [23]. During tissue repair, active cellular splitting can result in the occurrence, accumulation, and fixation of mutations, deletions, ectoplasias, and amplifications; these changes increase the risk of malignant transformation at the site of infection [24]. Furthermore, cellular experiments also showed that Cpn infection could transform mesothelial cells, which in turn could increase lung cancer risk [25]. Researchers have also established a Cpn infection-induced lung cancer model in rats [26].

Cpn infections are common among specific patient subgroups, particularly young people $[6,11]$, men $[12,13]$, and smokers $[6,8,11]$. Furthermore, the relationship between $C$ pn infection and lung cancer risk may vary when combined with environmental factors (e.g., age, sex, and smoking history). Among patients aged 60 years and older in our study, the association between Cpn IgA and lung cancer was statistically significant. This may be due to the increase of Cpn infection with age. In addition, a significant association was found between Cpn IgA or IgG and lung cancer among males and smokers. The OR values among smokers in our study were consistent with the 
results of other studies $[8,11]$. The current study also suggested that passive smokers with Cpn infection had a higher risk of lung cancer. The same carcinogens in cigarette smoke may induce lung cancer in people with a history of smoking and passive smoking [27-29]. Reactive nitrogen and oxygen species (RNOS) produced by smoking can activate NF- $\mathrm{kB}$ to promote the expression of inflammatory genes and directly or indirectly activate the production of inflammatory mediators through the regulation of various protein modifications and degradation [30]. Therefore, Cpn combined with smoking may promote lung cancer via elevated levels of inflammatory factors. Although many studies have indicated that smoking might induce lung cancer by aggravating lung inflammation [30, 31], further research on the underlying mechanisms of Cpn infection in the pathogenesis of lung cancer is still required.

Moreover, the current study also showed, for the first time, that Cpn IgG and IgA were more closely associated with lung cancer among alcohol drinkers. Alcohol exposure reduces airway mucociliary clearance through the progressive desensitization of ciliary response. As a result, this important innate primary defense mechanism is weakened. Chronic alcohol exposure also alters the adaptative immune response to pathogens and leads to an inflammatory response [32]. Therefore, Cpn combined with alcohol drinking may also promote lung cancer via elevated levels of inflammatory factors. Furthermore, the combined effects of Cpn IgG+ or IgA+ and family history of cancer on lung cancer were found. He et al. [33] proposed that non-small cell lung cancer (NSCLC) patients with a family history of cancer, especially a family history of lung cancer, might have a significantly higher incidence of epidermal growth factor receptor (EGFR) activating mutation. EGFR is an important predictive biomarker of EGFR tyrosine kinase inhibitors (TKIs) in NSCLC. Moreover, Cpn proteins have been shown to trigger lung cancer growth potential by DNA damage repair [23]. Therefore, Cpn infection might combine with a family history of cancer to induce lung cancer by mutation. However, further studies are warranted to confirm the results and explore the role of family history of cancer.

In this study, serum Cpn IgG and IgA were detected by MIF, which is the standard for serologic detection of Chlamydia infection. However, the use of MIF is limited by its subjectivity and reproducibility [34]. Therefore, our experiment was conducted by two different people. A skilled technician performed the preliminary experiment, and the second person conducted a blind interpretation of the results. Furthermore, $10 \%$ of the samples were randomly selected for retesting. Previously published studies have had varying definitions for "chronic" chlamydial infection. For example, one study
[6] used a combination of specific IgA titers (1:16 or higher) and immune complex titers (1:4 or greater), whereas others have used IgA titers of 1:64 or higher [10] or IgG titers of 1:512 or higher [12-14]. Moreover, in several studies $[7,8,11,35,36] \operatorname{IgG}$ antibody titers of 1:16 or more were considered as evidence of past or present Cpn infection, whereas IgA antibody titers of 1 : 16 or more were considered to indicate chronic infection. Thus, IgG and IgA antibody detection were used to explore the relationship between Chlamydia and lung cancer in the current study.

The present study is the most extensive retrospective case-control study to evaluate the role of $\mathrm{Cpn}$ in lung cancer pathogenesis. Meanwhile, stratification and multivariate analysis were used to identify possible effect modifiers associated with $\mathrm{Cpn}$ and lung cancer. However, several potential limitations in this study should be considered. First, there were some unavoidable selection and recall biases. Second, it is difficult to explore the causal inference between Cpn infection and lung cancer when the blood for the study is collected after the cancer diagnosis to determine $\mathrm{Cpn}$ infection status. Third, our results may underestimate the effect of the association between Cpn infection and lung cancer due to nondisaggregated misclassification bias caused by the preselected criteria for determining chlamydial infection. Finally, although Cpn IgG+ means patients have at some point had a Cpn infection, Cpn IgA+ only means patients have present or chronic Cpn infection because of the short half-life of Cpn IgA. Despite these limitations, our findings are biologically plausible. Studies have suggested that higher infection rates in patients with cancer are often caused by the immunosuppressive effects of cancers [6]. However, studies in which serum was collected before lung cancer diagnosis showed that the association between serum Cpn and lung cancer still existed when blood samples obtained 1 to 5 years before diagnosis were excluded, suggesting that $\mathrm{Cpn}$ infection pre-dated the cancer diagnosis [8].

\section{Conclusion}

In conclusion, our results show that $\mathrm{Cpn}$ infection might be an independent risk factor for lung cancer and it has combined effects with smoking, passive smoking, and a family history of cancer. However, in order to make causal inferences about Cpn infection and lung cancer, well-designed cohort studies and randomized controlled trials are needed to minimize the effect of disease on antibody titers, reduce selection bias, and better adjust for potential confounders. Modifications of these studies would allow tests to clarify the pathogenic role of $\mathrm{Cpn}$ infection in lung cancer. 


\section{Supplementary information}

Supplementary information accompanies this paper at https://doi.org/10. 1186/s12885-020-07418-8.

\section{Additional file 1.}

\section{Abbreviations}

API: Attributed proportion of interaction; BMI: Body mass index Cpn: Chlamydia pneumonia; Ctr: Chlamydia trachomatis; Cps: Chlamydia psittaci; Cls: Confidence intervals; EGFR: Epidermal growth factor receptor; MIF: Micro-immunofluorescence; ORs: Odds ratios; RERI: Relative excess risk of interaction; RNOS: Reactive nitrogen and oxygen species; S: The synergy index; TKls: Tyrosine kinase inhibitors

\section{Acknowledgments}

We thank all the staff from the Department of Thoracic Surgery, The first affiliated hospital of Fujian Medical University. Moreover, we also would like to express our appreciation to the patients who participated in our study.

\section{Authors' contributions}

XX, LZQ and HF conceived of the study. XWM and XQP carried out the experiments, participated in the drafted the manuscript. QML, and KSL collected samples. HF and CL participated in the design of the study and helped to review the manuscript. XWM and LZQ performed the statistical analysis. All authors read and approved the final manuscript.

\section{Funding}

This study was supported by grants from the National Natural Science Foundation of China (Nos 81402738), Fujian Provincial Health Research Talents Training Program Medical Innovation Project (Nos 2019-CX-33), Fujian Program for Outstanding Young Researchers in University awarded by Education Department of Fujian (Nos 2017B019), the National Key Research and Development Program of China (Nos 2017YFC0907100) and Startup Fund of Fujian Medical University for scientific research (Nos 2019QH1297).

\section{Availability of data and materials}

The datasets used and/or analyzed during the current study are available from the corresponding author on reasonable request.

\section{Ethics approval and consent to participate}

The study was approved by the Institutional Review Board of Fujian Medical University (Fuzhou, China). All participants signed informed consent forms.

\section{Consent for publication}

Not Applicable.

\section{Competing interests}

There are no financial or non-financial competing interests.

\section{Author details}

${ }^{1}$ Department of Epidemiology and Health Statistics, School of Public Health, Fujian Medical University, Fuzhou 350108, China. ${ }^{2}$ The United Innovation of Mengchao Hepatobiliary Technology Key Laboratory of Fujian Province, Mengchao Hepatobiliary Hospital of Fujian Medical University, Fuzhou 350025, China. ${ }^{3}$ The Liver Center of Fujian Province, Fujian Medical University, Fuzhou 350025, China. ${ }^{4}$ Department of Health and Quarantine, The Xiamen Customs of the People's Republic of China, Xiamen 361001, China. ${ }^{5}$ Department of Thoracic Surgery, The First Affiliated Hospital of Fujian Medical University, Fuzhou 350005, China. ${ }^{6}$ Fuzhou Center for Disease Control and Prevention, Fuzhou 350004, China. ${ }^{7}$ Department of Preventive Medicine, School of Public Health, Fujian Medical University, Fuzhou 350108, China. ${ }^{8}$ Medical Department, The Affiliated Hospital of Putian University, Putian 351100, China.
Received: 11 February 2020 Accepted: 15 September 2020

Published online: 22 September 2020

\section{References}

1. Bray F, Ferlay J, Soerjomataram I, Siegel RL, Torre LA, Jemal A. Global cancer statistics 2018: GLOBOCAN estimates of incidence and mortality worldwide for 36 cancers in 185 countries. CA Cancer J Clin. 2018:68(6):394-424.

2. Dela Cruz CS, Tanoue LT, Matthay RA. Lung cancer: epidemiology, etiology, and prevention. Clin Chest Med. 2011;32(4):605-44.

3. de Martel C, Ferlay J, Franceschi S, Vignat J, Bray F, Forman D, et al. Global burden of cancers attributable to infections in 2008: a review and synthetic analysis. Lancet Oncol. 2012;13(6):607-15.

4. Engels EA. Inflammation in the development of lung cancer: epidemiological evidence. Expert Rev Anticancer Ther. 2008:8(4):605-15.

5. Brenner DR, Fanidi A, Grankvist K, Muller DC, Brennan P, Manjer J, et al. Inflammatory cytokines and lung Cancer risk in 3 prospective studies. Am J Epidemiol. 2017;185(2):86-95.

6. Laurila AL, Anttila T, Läärä E, Bloigu A, Virtamo J, Albanes D, et al. Serologica evidence of an association between chlamydia pneumoniae infection and lung cancer. Int J Cancer. 1997;74(1):31-4.

7. Anttila $T$, Koskela $\mathrm{P}$, Leinonen $\mathrm{M}$, Laukkanen $\mathrm{P}$, Hakulinen $\mathrm{T}$, Lehtinen $\mathrm{M}$, et al. Chlamydia pneumoniae infection and the risk of female early-onset lung cancer. Int J Cancer. 2003;107(4):681-2

8. Chaturvedi AK, White E, Jackson LA, Thornquist MD, Gaydos CA, Goodman $\mathrm{GE}$, et al. Chlamydia pneumoniae infection and risk of lung cancer. Cancer Epidemiol Biomarkers Prev. 2004;13(10):1624-30.

9. Chaturvedi AK, Gaydos CA, Agreda P, Holden JP, Chatterjee N, Goedert JJ, et al. Chlamydia pneumoniae infection and risk for lung cancer. Cancer Epidemiol Biomark Prev. 2010;19(6):1498-505.

10. Koyi H, Brandén E, Gnarpe J, Gnarpe H, Arnholm B, Hillerdal G. Chlamydia pneumoniae may be associated with lung cancer. Preliminary report on a seroepidemiological study. Apmis. 1999:107(9):828-32.

11. Jackson LA, Wang SP, Nazar-Stewart V, Grayston JT, Vaughan TL. Association of Chlamydia pneumoniae immunoglobulin a seropositivity and risk of lung cancer. Cancer Epidemiol Biomark Prev. 2000;9(11):1263-6.

12. Koyi H, Brandén E, Gnarpe J, Gnarpe H, Steen B. An association between chronic infection with chlamydia pneumoniae and lung cancer. A prospective 2-year study. Apmis. 2001;109(9):572-80.

13. Kocazeybek B. Chronic Chlamydophila pneumoniae infection in lung cancer, a risk factor: a case-control study. J Med Microbiol. 2003;52(Pt 8): $721-6$.

14. Koh WP, Chow VT, Phoon MC, Ramachandran N, Seow A. Lack of association between chronic Chlamydophila pneumoniae infection and lung cancer among nonsmoking Chinese women in Singapore. Int J Cancer. 2005:114(3):502-4.

15. Smith JS, Kumlin U, Nyberg F, Fortes C, Zaridze D, Ahrens W, et al. Lack of association between serum antibodies of chlamydia pneumoniae infection and the risk of lung cancer. Int J Cancer. 2008;123(10):2469-71.

16. Liu Z, Su M, Yu SC, Yin ZH, Zhou BS. Association of Chlamydia pneumoniae immunoglobulin $\mathrm{G}$ antibodies with the risk of lung cancer among nonsmoking women in Liaoning, China. Thoracic cancer. 2010;1(3):126-9.

17. He F, Xiao RD, Lin T, Xiong WM, Xu QP, Li X, et al. Dietary patterns, BCMO1 polymorphisms, and primary lung cancer risk in a Han Chinese population: a case-control study in Southeast China. BMC Cancer. 2018;18(1):445.

18. Zhao W, Cong L. Physical activity evaluation: metabolic equivalent intensity levels and evaluation of different physical activity. Wei Sheng Yan Jiu. 2004; 33(2):246-9.

19. Andersson T, Alfredsson L, Källberg H, Zdravkovic S, Ahlbom A. Calculating measures of biological interaction. Eur J Epidemiol. 2005;20(7):575-9.

20. Hua-Feng $X$, Yue-Ming W, Hong L, Junyi D. A meta-analysis of the association between chlamydia pneumoniae infection and lung cancer risk. Indian J Cancer. 2015:52(Suppl 2):e112-5.

21. Zhan P, Suo LJ, Qian Q, Shen XK, Qiu LX, Yu LK, et al. Chlamydia pneumoniae infection and lung cancer risk: a meta-analysis. Eur J Cancer (Oxford, England : 1990). 2011;47(5):742-7.

22. Sessa R, Santino I, Di Pietro M, Schiavoni G, Ripa C, Galdiero M, et al. No evidence of involvement of chlamydia pneumoniae in lung cancer by means of quantitative real-time polymerase chain reaction. Int J Immunopathol Pharmacol. 2008;21(2):415-20. 
23. Khan S, Imran A, Khan AA, Abul Kalam M, Alshamsan A. Systems biology approaches for the prediction of possible role of chlamydia pneumoniae proteins in the etiology of lung Cancer. PLoS One. 2016;11(2):e0148530.

24. Preston-Martin S, Pike MC, Ross RK, Jones PA, Henderson BE. Increased cell division as a cause of human cancer. Cancer Res. 1990;50(23):7415-21.

25. Rizzo A, Carratelli CR, De Filippis A, Bevilacqua N, Tufano MA, Buommino E. Transforming activities of chlamydia pneumoniae in human mesothelial cells. Int Microbiol. 2014;17(4):185-93.

26. Chu DJ, Guo SG, Pan CF, Wang J, Du Y, Lu XF, et al. An experimental model for induction of lung cancer in rats by chlamydia pneumoniae. Asian Pacific J Cancer Prev. 2012;13(6):2819-22.

27. Apelberg BJ, Hepp LM, Avila-Tang E, Gundel L, Hammond SK, Hovell MF, et al. Environmental monitoring of secondhand smoke exposure. Tob Control. 2013;22(3):147-55.

28. Smith CJ, Hansch C. The relative toxicity of compounds in mainstream cigarette smoke condensate. Food Chem Toxicol. 2000;38(7):637-46.

29. ProulX LI, Castonguay A, Bissonnette EY. Cytokine production by alveolar macrophages is down regulated by the alpha-methylhydroxylation pathway of 4-(methylnitrosamino)-1-(3-pyridyl)-1-butanone (NNK). Carcinogenesis. 2004;25(6):997-1003.

30. Li T, He X, Chen Y. Mechanism of lung cancer and chronic obstructive pulmonary disease. Zhong Nan Da Xue Xue Bao Yi Xue Ban. 2017:42(10): $1212-6$.

31. Walser T, Cui X, Yanagawa J, Lee JM, Heinrich E, Lee G, et al. Smoking and lung cancer: the role of inflammation. Proc Am Thorac Soc. 2008:5(8):811-5.

32. Arvers P. Alcohol consumption and lung damage: dangerous relationships. Rev Mal Respir. 2018;35(10):1039-49.

33. He Y, Li S, Ren S, Cai W, Li X, Zhao C, et al. Impact of family history of cancer on the incidence of mutation in epidermal growth factor receptor gene in non-small cell lung cancer patients. Lung Cancer. 2013;81(2):162-6.

34. Littman AJ, Jackson LA, White E, Thornquist MD, Gaydos CA, Vaughan TL. Interlaboratory reliability of microimmunofluorescence test for measurement of chlamydia pneumoniae-specific immunoglobulin a and $G$ antibody titers. Clin Diagn Lab Immunol. 2004;1 1(3):615-7.

35. Mestecky J, McGhee JR. Immunoglobulin a (IgA): molecular and cellular interactions involved in IgA biosynthesis and immune response. Adv Immunol. 1987:40:153-245.

36. von Hertzen L, Leinonen M, Surcel HM, Karjalainen J, Saikku P. Measurement of sputum antibodies in the diagnosis of acute and chronic respiratory infections associated with chlamydia pneumoniae. Clin Diagn Lab Immunol. 1995;2(4):454-7.

\section{Publisher's Note}

Springer Nature remains neutral with regard to jurisdictional claims in published maps and institutional affiliations.

Ready to submit your research? Choose BMC and benefit from:

- fast, convenient online submission

- thorough peer review by experienced researchers in your field

- rapid publication on acceptance

- support for research data, including large and complex data types

- gold Open Access which fosters wider collaboration and increased citations

- maximum visibility for your research: over $100 \mathrm{M}$ website views per year

At $\mathrm{BMC}$, research is always in progress.

Learn more biomedcentral.com/submissions 